\title{
ETNIA XAKRIABÁ, SIGNO PRECONCEITO: TRAJETÓRIAS CONVERGENTES
}

\author{
WILLIAM CÉSAR LOPES DOMINGUES ${ }^{1}$ \\ $U F P A$
}

\begin{abstract}
RESUMO: Nasci xakriabá, mas vivo no Médio Xingu, adotado pelos Asurini. Sou pedagogo e professor no câmpus de Altamira (PA) da Universidade Federal do Pará. Hoje estou fazendo mestrado em Antropologia, no Programa de Pós-Graduação em Antropologia (PPGA) dessa universidade, por conta das ameaças que sofro a propósito de Belo Monte.
\end{abstract}

PALAVRAS-CHAVE: povos indígenas; trajetória indígena; preconceito; discriminação.

ABSTRACT: I was born Xakriabá, but the Asuriri adopted me and now I live in Médio Xingu. I'm an educator and a professor at the Federal University of Pará. I'm currently studying for my Master's degree in Anthropology at the same university, on account of the threats I've received.

KEYWORDS: indigenous peoples; indigenous trajectories; prejudice; discrimination.

\section{Longe de Minas Gerais}

Sob o signo do preconceito, nasci indígena xakriabá. Nasci em Brasília, no Planalto Central, longe do Semiárido mineiro que, mais tarde saberia por meio dos velhos, havia me parido, a terra dos meus ancestrais. Meus pais, talvez fugindo da escassez, do preconceito e dos conflitos agrários, ou em busca da terra da boa vivência, foram para lá ajudar a fazer Brasília e, como muitos outros indígenas que fizeram o mesmo trajeto, se assentaram num dos cantos isolados da cidade -

\footnotetext{
${ }^{1}$ Ou Uwira, como me chamo entre os Asurini. Sou indígena do povo Xakriabá que se fez pedagogo de formação e hoje é mestrando em Antropologia junto à Universidade Federal do Pará (UFPA). Tenho atuado, nos últimos quinze anos, com a formação de Conselheiros de Saúde Indígena. Sou docente do curso de Etnodesenvolvimento da UFPA, no qual ministro, entre outras, a disciplina Saúde e Sociedade, no câmpus em Altamira (PA). E-mail: uwiraete@gmail.com.
} 
hoje, o hipervalorizado Setor Noroeste, onde fica o Recanto do Pajé, motivo de disputas judiciais com o governo do Distrito Federal. Cresci entre o centro do poder do país e o centro do universo, a terra de meus ancestrais, com a qual nunca perdi o contato. Menino para a sociedade onde me via inserido, mas homem feito para meu povo, estive envolvido em toda a efervescência política da luta pelas eleições diretas e pela garantia dos direitos de nosso povo na Constituinte. Eu não era líder de nada, apenas mais um guerreiro lutando para garantir o direito de continuar existindo como diferente, como povo distinto dos demais povos que formam esse país.

Viver em Brasília nesse período me possibilitou conhecer os grandes líderes de nosso povo e aprender com sua força e coragem que era preciso lutar, porque a invasão ocorrida há quase quinhentos anos ainda não tinha terminado. Chicão Xukuru, Maninha, Raoní, Celestino, Rosalino e tantos outros tombados na luta foram meus principais mestres na escola de ser líder, de aprender a representar povos e anseios coletivos. Em casa eu aprendia que era preciso trabalhar duro e estudar muito para poder de alguma forma lidar com o preconceito por ser e sentir-se diferente. Meu pai me embruteceu para o mato, para saber viver e andar, comer, beber e lidar com os cantos e encantos de rios e matas; e minha mãe e avó, para ter ouvidos atentos a toda boa instrução, para ouvir e ensinar a outros, contar e recontar histórias antigas de mundos hoje vivos apenas na memória.

Não obstante a oportunidade de conviver com esses grandes guerreiros, eu tinha que lidar, no Planalto Central, uma terra considerada "sem índios", com o forte preconceito que eu não conseguia entender, afinal de contas, não havia um letreiro em mim que me identificasse e eu não tinha o fenótipo característico que se exigia para ser "índio", era meu próprio orgulho de ser indígena que me traía e me levava a me reconhecer e declarar indígena. Dessa forma, o preconceito vinha, por um lado, por ser indígena e, por outro, por não parecer com o que se aceitava como indígena, por morar em Brasília e por, de fato, ser diferente das pessoas que viviam ali.

Fui uma criança que aprendeu a ler bem tarde para os padrões ocidentais; minha família morava, embora muito perto do centro de poder, em um lugar relativamente isolado em minha infância, de forma 
que eu e minhas três irmãs tínhamos apenas uns aos outros para todas as brincadeiras. Naqueles idos da década de 1970, era costume as famílias adquirirem, não sem muito custo, enciclopédias encadernadas que serviam para adornar as salas; os livros não estavam ali para ser manuseados, era apenas para mostrar aos visitantes o "prestígio" da família. Eu me escondia por detrás de um sofá e passava horas absorto entre figuras e palavras que ia aprendendo. Sobre povos, guerras, histórias fantásticas e romances tórridos. Quando aprendi a ler de fato, mais ou menos quando cheguei à antiga quinta série, passei a devorar as palavras que acompanhavam as figuras que eu conhecia tão bem.

\section{Entre os Asurini, fui parido guerreiro}

No final da década de 1990, eu estava "formado" como técnico em administração e fazia um curso de técnico em enfermagem, porque eu queria de alguma forma poder trabalhar com pessoas, tocá-las, ajudálas de uma maneira mais prática. Foi nesse período, durante uma das muitas conferências de povos indígenas em Brasília que conheci os Asurini do Xingu. Da empatia imediata veio o convite para conhecer a aldeia e passar um tempo por lá atuando voluntariamente como técnico em enfermagem, uma vez que havia sido criado o Subsistema de Atenção à Saúde Indígena, que regulava a responsabilidade de cuidar da saúde indígena, retirada da Fundação Nacional do Índio (FUNAI) com a criação do Sistema Único de Saúde (SUS). Mas esse subsistema não havia sido ainda implantado, gerando falta de assistência nas aldeias. Pouco tempo depois, eu chegava à aldeia Kwatinemu, na margem direita do Rio Xingu, a cerca de cem quilômetros de Altamira (PA).

$\mathrm{Na}$ aldeia eu comecei a atuar como técnico em enfermagem. Como faltavam também professores, minha esposa e depois eu mesmo, após aprender a língua, começamos a atuar também como professores bilíngues, alfabetizando as crianças em sua própria língua. Com o passar dos anos e a efetivação do subsistema, passei a atuar apenas durante as folgas do técnico enviado pela Fundação Nacional de Saúde (FUNASA) para a aldeia. O convívio, a vida comum, de roça, caça e pesca partilhados no cotidiano e a empatia difícil de explicar fizeram com que 
fôssemos adotados pelos Asurini, que nos deram nomes, famílias e papéis sociais bem definidos dentro da comunidade.

\section{Amansando a academia}

$\mathrm{Na}$ aldeia, naquele tempo, não tínhamos ainda água encanada e nem energia elétrica, todas as relações, exceto durante os rituais, ocorriam durante o dia, à noite todos ficavam em suas casas se escondendo dos muitos mosquitos. Eu costumava, sempre que ia à cidade, levar muitos livros e os lia durante a noite, deitado na rede com uma lanterna entre os dentes ou presa entre o pescoço e o ombro, assim conheci a filosofia grega e depois Hobbes, Rousseau, Weber, Marx, Engels, Durkheim, Kierkgaard, Nietzsche. Essas leituras me levavam sempre a outras, instigado pelo convívio com os velhos asurini, com quem aprendia sobre o que era ser Awaete $^{2}$, como todas as instâncias do mundo eram essencialmente humanas, e por isso mesmo humanizáveis, e como deveria lidar com cada uma delas. Essas reflexões e o convívio com pesquisadores que visitavam a aldeia, entre os quais destaco Regina Müller, Fabíola Silva e Oseas Beserra, me levaram à antropologia. Li, inicialmente, grande parte da obra de Darcy Ribeiro, porque havia uma coleção na escola, e daí foi um pulo até aqueles que depois descobri serem os conhecidos como os pais da antropologia: Tylor, Spencer, Malinowski, Boas, Pritchard. Tudo me parecia fascinante, sobretudo pensava em questões com as quais ainda não sabia que a antropologia lidava, em relação ao papel do autor e o efeito das narrativas que faziam.

Cerca de quatro anos depois de estarmos morando na aldeia, começamos a estudar no campus da Universidade Federal do Pará (UFPA) em Altamira, no curso intervalar de Pedagogia, o que possibilitava que continuássemos morando na aldeia e estudássemos nas férias. Esse processo de ir estudar na universidade foi um processo negociado, partilhado com a comunidade como parte de um projeto maior de, segundo os mais sábios, "amansar" a universidade e,

\footnotetext{
${ }^{22}$ Etnônimo do povo Asurini do Xingu que significa "gente de verdade".
} 
conhecendo-a, torná-la conhecida dos parentes e abrir suas portas para eles.

Nesse período fui indicado pelas lideranças indígenas para ser o vice-presidente do recém-criado Conselho Distrital de Saúde Indígena (CONDISI), cargo que ocupei por dois mandatos, sendo depois eleito como presidente por mais dois mandatos intercalados. Minha atuação no CONDISI foi pautada por duas premissas principais: eu não abria mão de um processo contínuo de capacitação dos conselheiros e nem de consultá-los sobre quaisquer assuntos que exigissem tomadas de decisões. Esta atuação possibilitou que eu conhecesse todas as aldeias, parentes e lideranças da região do Médio Xingu, que dialogasse com eles e que juntos iniciássemos o que hoje pode ser considerado um movimento indígena na região. Minha posição perante essas lideranças sempre foi a de um representante deles, não uma liderança. Eu tinha, então, em Luís Xipaia, Joaquim Curuaia, Tedjore Xikrin, Manuka Asurini, Bepmunhti Xikrin, Maria Xipaia, Manoel Juruna, Tukum e outros, novos professores e companheiros de lutas também novas.

A ideia de amansamento ou pacificação dos "brancos" não é nova entre a maioria dos povos indígenas do Brasil. Albert e Ramos (2002) alertam, no entanto, para o parco interesse antropológico sobre os fatos e efeitos do que chamaram de "situações de contato", com trabalhos limitados à abordagem dos "mitos do branco". Darcy Ribeiro, ao contar a história de Uirá, o índio que saiu à procura de Maíra no mundo dos brancos, por assim dizer, aborda também esta questão.

Durante esse período na Universidade, tive a oportunidade de conhecer a Dra. Jane Beltrão. Estávamos em plena luta contra a construção da hidrelétrica de Belo Monte e ela atendeu nosso convite para ministrar um minicurso sobre educação indígena na $3^{\text {a Semana de }}$ Estudos Pedagógicos, que eu, como um dos coordenadores do Centro Acadêmico de Pedagogia, do qual fui um dos criadores, estava coordenando. A partir desse contato surgiram as primeiras discussões sobre a possibilidade de criarmos, na UFPA em Altamira, um curso para formação para indígenas que fosse multidisciplinar, de modo a formar não apenas professores indígenas, mas parentes que pudessem atuar junto a seus povos visando atender as suas necessidades e projetos de vida. 
O resultado dessa luta, travada dentro e fora da Universidade, foi a criação do curso de Etnodesenvolvimento, que, com a colaboração de parceiros importantes de outros movimentos sociais, passava a abranger também quilombolas, ribeirinhos, agricultores tradicionais e demais povos tradicionais. Novos mestres se colocavam em cena, pesquisadores engajados nas lutas por emancipação social me ensinavam a usar canetas, papéis e falas como armas. Zélia Amador de Deus, Jane Beltrão, Alex Fiúza, Rainério Meireles e tantos outros que foram tão importantes nesse momento de conquista e de formação.

A militância no Conselho Distrital de Saúde Indígena (CONDISI), ao me levar para as aldeias dos outros parentes, me conduziu também ao Fórum dos Presidentes de CONDISI, que tive a oportunidade de coordenar por dois mandatos. Ali tive a oportunidade de, no convívio com os mestres Carmem Pankararu, Yssô Truká, Ancelmo Tuxá, Nélson Rikbatsa, Hilário Kadiwéu, Edmilson Terena, Midas e tantos outros, aprender muito sobre como a diversidade de nosso povo pensa saúde e doença, como está organizado o atendimento oficial à saúde e nossas práticas tradicionais de cuidados com a saúde. A partir do Fórum, passei a representar nosso povo na Comissão Intersetorial de Saúde Indígena (CISI) e na Subcomissão de Saúde Indígena do Conselho Nacional de Política Indigenista (CNPI).

Após um tempo de militância intensa, resolvi que era hora de voltar a viver na aldeia, entre os Asurini, onde me construí como sujeito indígena, deixar a frente de intermináveis lutas e viver o cotidiano simples e tão rico da aldeia, trabalhar na roça, caçar, pescar e partilhar a vida e o que aprendi nesse tempo. De volta à aldeia, criamos uma associação e começamos a planejar que tipo de futuro queríamos, nos pensando para nós e para nossos filhos. O perigo anunciado da hidrelétrica se aproximava vertiginoso e letal de nossas aldeias e, com a necessidade cada vez maior de apoio e de interlocução, os parentes pressionaram a FUNAI para que eu fosse colocado como chefe de posto da aldeia, cargo que ocupei até a reestruturação da FUNAI, quando o mesmo foi extinto. A volta à aldeia havia sido motivada também por uma série de ameaças e atentados devido a denúncias sobre desvios de recursos da saúde indígena, velhos inimigos se juntavam a novos, por 
conta dos muitos confrontos com pescadores ilegais, madeireiros e grileiros de terras.

Assim que saí na FUNAI, tive um sério problema de saúde que me obrigou a ir morar na cidade. Voltei ao CONDISI e passei a atuar como professor convidado no recém-criado curso de Etnodesenvolvimento, mais uma vez com a anuência e aprovação dos parentes. Quando abriu um concurso para professor efetivo do curso, fui para a aldeia consultar os velhos e as lideranças se eles achavam que eu deveria tentar fazer o concurso, e eles me disseram que eu precisava continuar tentando amansar a universidade para eles porque os meninos que nós ensinamos na escola estavam fazendo o ensino médio modular, que também foi motivo de muitas lutas, e depois eles iam entrar na universidade. Com esta tarefa fiz o concurso e fui aprovado.

\section{O tempo das ameaças}

Passei a dividir meu tempo entre o curso de Etnodesenvolvimento e a militância na saúde indígena com a luta pela garantia de direitos frente à construção iminente de Belo Monte. O cenário era muito complicado, a desassistência quase completa por parte do Estado, uma reformulação malfeita e não discutida com nosso povo na FUNAI, e a cada dia mais presente possibilidade de mais um cataclisma com a inundação de nosso mundo pela barragem, empurrava nosso povo para rumos sombrios, levando nossos jovens para o abuso do álcool e de outras drogas e para a violência daí decorrente. Os constantes entraves que conseguíamos colocar para o avanço das obras nos angariava inimigos de todos os lados. Todos os que queriam, por um motivo ou por outro, a construção da barragem se juntavam contra nós, alimentando antigos ódios e preconceitos.

Passei, então, a ser alvo de ameaças mais constantes, que culminaram com dois atentados sofridos em 2014, onde fui baleado e, por conta disso, obrigado a sair temporariamente de Altamira. Se, por um lado, isso me trouxe sérias consequências, por outro, me deu a oportunidade de iniciar o mestrado em Antropologia aqui no Programa de Pós-Graduação em Antropologia (PPGA). Os parentes de Altamira 
sofreram comigo todas as minhas dores e, mesmo morando fora e só podendo retornar com escolta, não permitiram que eu abandonasse a presidência do CONDISI, cargo que ocupava novamente.

Altamira, embora seja uma cidade construída em território reconhecidamente indígena, talvez até mesmo por isso, é uma cidade com um forte preconceito em relação aos povos indígenas. Ali continuei lidando com duas formas de preconceito, por ser indígena e por não me enquadrar no estereótipo, agora com o agravante de que possivelmente eu estaria tentando obter alguma vantagem me identificando como indígena e de um povo que não é daquela região. A desconfiança inicial era muito grande e só findou a partir do momento em que os próprios parentes locais começaram a participar de reuniões no cenário nacional e conheceram meu povo e outros parentes de outros lugares que já me conheciam.

\section{Referências bibliográficas}

ALBERT, Bruce. O ouro canibal e a queda do céu: uma crítica Xamânica da economia política da natureza (Yanomami). In: ALBERT, Bruce; RAMOS, Alcida Rita (Org.). Pacificando o Branco: cosmologias do contato no Norte-Amazônico. São Paulo: UNESP, 2002. p. 239-276.

ALBERT, Bruce; RAMOS, Alcida Rita (Org.). Pacificando o Branco: cosmologias do contato no Norte-Amazônico. São Paulo: UNESP, 2002.

Recebido em: 28/09/2016 * Aprovado em: 21/10/2016 * Publicado em: 31/12/2016 